\title{
Psychological Risk Factors for Chronic Apical Periodontitis: A Pilot Cross Sectional Study
}

\author{
Ritu Sharma ${ }^{1}$, J agadeesh H.G ${ }^{2}$, Renuka J Bathi ${ }^{3}$, Uday K. Sinha ${ }^{4}$
}

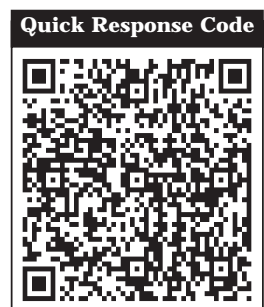

doi: $10.5866 / 2014.641664$

${ }^{1}$ Department of Conservative Dentistry \& Endodontic School of Dental Sciences, Sharda University,

Greater Noida, India.

2Department of Prosthodontics

School of Dental Sciences, Sharda University,

Greater Noida, India.

${ }^{3}$ Renuka J Bathi,

Department of Oral Medicine \& Radiology

School of Dental Sciences, Sharda University,

Greater Noida, India.

${ }^{4}$ Department of Clinical Psychology

Institute of Human Behaviour \& Allied Sciences

(IHBAS) New Delhi, India.

\section{Article Info:}

Received: J uly 10, 2014

Review Completed: August 10, 2014

Accepted: November 12, 2014

Available Online: J anuary, 2015 (www.nacd.in)

(c) NAD, 2015 - All rights reserved

\section{Email for correspondence:}

ritu.sharma@sharda.ac.in, drriturs@gmail.com

\begin{abstract}
:
The relationship between apical periodontitis and psychological factors remains unexplored till date. The goal of this study was to explore if, there was an association, between chronic apical periodontitis, and psychological risk factors. A 30 item Psychological Risk Factors Questionnaire was administered to 60 patients; 30 cases (10 females, 20 males, mean age 23.53 years \pm 3.49 S.D.), and 30 controls ( 5 females, 25 males, mean age 23.43 years \pm 3.95 S.D.). Cases (patients with chronic apical periodontitis) demonstrated significant presence of four psychol ogi cal risk factors. Patients with temperamental/ personality characteristic had 25.4 times higher odds of having chronic apical periodontitis.
\end{abstract}

Key words: Anxiety, apical periodontitis, psychological factors, dental anxiety, endodontics

\section{INTRODUCTION}

Endodontic disease is now being associated with chronic systemic diseases, such as type 2 diabetes mellitus and coronary atherosclerotic disease. ${ }^{1-4}$ Periodontal disease, which shares its etiopathology with apical periodontitis, is provably associated with these chronic systemic diseases. ${ }^{5} \mathrm{~A}$ known common risk factor for both periodontal and chronic systemic diseases, is psychological stress. Dental caries, the primary etiological factor for chronic apical periodontitis, is also associated with psychological stress. ${ }^{6-9}$ The effects of stress such as: immune

\section{Indian Journal of Dental Advancements}

Journal homepage: www. nacd. in 
system alteration; altered flow and composition of saliva; intake of fatty and sugary diet; erratic oral hygiene practices; and dental anxiety (i.e. fear of dentist and dental treatment) are said to be responsible for this association. ${ }^{6,7,9-16}$

Psychological stress (which is positively associated with oxidative stress) is a result of the environmental demands, exceeding or taxing, the adaptive capacity of an organism. ${ }^{17}$ This causes psychological and biological changes, putting people, at risk for disease. ${ }^{18}$ Response to stress is generated at the levels of physiology, cognition and behaviour. ${ }^{19}$

The psycho-physiological response to a stressor may act as causal factor; inhibit host defence and resistance; disrupt existing pathology or trigger acute clinical events. Mainly three systems operationalizethis neuroendocrine sympathetic and parasympathetic system; and immune system. Stress related cognitive problems include difficulty in recognition of symptoms, and decisions to seek health intervention. Stress also causes behavioural changes like smoking, drinking al cohol, high calorie diet intake, and disregarding medical advice. ${ }^{19}$

Psychological stress affects both exogenous factors (i.e. microbes, toxins, trauma etc.) and endogenous factors (i.e. host inflammatory response, host metabolic by-products) responsible for the development of chronic apical periodontitis (CAP). ${ }^{19}$ It may be a risk factor for CAP. No reported study has investigated such a possibility. The present pilot investigation aimed to test the hypothesis that CAP may be associated with psychological risk factors.

\section{Materials and Methods}

\section{Sampling}

The university ethical committee, upon submission and subsequent discussion of study protocol, gave the ethical clearance for the present research. Convenient sample of consecutive patients of middle socioeconomic status (minimum high school education; family income 200,000-500,000; residing in the neighbouring suburbs), $18-30$ years of age, attending the institute out-patient department, from February 2013 to May 2013 was used. Totally 60 patients; 30 cases (10 females, 20 males, mean age 23.53 years $\pm 3.49 \mathrm{SD}$ ), and 30 controls ( 5 females, 25 males, mean age 23.43 years $\pm 3.95 \mathrm{SD}$ ) were sel ected. Patients presenting at least one tooth with chronic apical periodontitis (diagnosed through history, thermal/electric pulp test, and radiograph) were categorised as cases. Presence of an obvious cause of pulp demise (caries or trauma); loss of Iamina dura or periapical radiolucency; and a negative pulp vitality test were the criteria used to select CAP case. Patients with no teeth having pulpal pathology (pulpitis/necrosis), or related periapical pathology, were selected as controls. Exclusion criteria were patients with chronic generalised periodontitis; acute symptoms of pulpal / periapical pathology; systemic disease; and mental disabilities. Recruits gave a written informed consent. Clinician selecting the recruits' noted their personal data, and examination findings. The filled form was then folded and stapled such that the noted findings were not visible. The form was then randomly coded and recruitments per group were noted in a register.

\section{Questionnaire}

Another investigator blinded to the patient grouping administered the 30 item Psychological Risk Factors Questionnaire (PRFQ) (Attachment1) to the patient in a separate room. A study has tested the reliability and construct validity of this psychological questionnaire, for the Indian population, previously. ${ }^{20}$

The questionnaire is available in both English and $\mathrm{Hindi}$ (native language). The investigator pretested the questionnaire on 10 patients to assess content validity and obtain a uniform way of asking questions. The qualitative description of each answer was not attempted. I nvestigator noted the findings, and coded the questionnaireform, with the same code as examination findings' form. the PRFQ questionnaire that has been framed to measure individual's cognitive and affective attributes as potential risk factors. The questionnaire measures the following psychological constructs: Perceived stress (PS), negative affective regulation (NAR), maladaptive coping styles (MCS), personality/ temperamental characteristics (P/TC) and negative cognitive schemas (NCS). Eight questions analysed PS; four analysed NAR \& MCS; five analysed T/PC 
\& NCS (Attachment 2). Since many patients in the selected age group were unmarried, sixth social and emotional support system construct (analysed by 4 questions) was not measured for the present study. Each question has four possible options, out of which the most appropriate option for the given individual has to be selected. Following scoring method is adopted. Score1- Not at all/ occasionally; Score 2Somewhat/ Sometimes; Score 3- Much/Most of the time; Score 4- Very much/Always. Average score of more than 2.5, for any of the five psychological factors, indicated the significant presence of that factor. The scores for each factor were calculated for each patient and significant scores were tabulated. The sealed envelopes were then opened to group the patient under cases/ controls.

\section{Statistical analysis}

Pearson Chi-Square test/Fisher's exact test determined thestatistical significance of categorical variables (PS, NAR etc.). Multiple logistic regression analysis was used to determine the optimum combination of significant predictors (psychological constructs) for CAP. Level of statistical significance was taken as $p \leq 0.05$. SPSS version 17.2 software was used for data analysis.

\section{Results}

Analysis of 60 patients of middle socioeconomic status, 18- 30 years old; 30 cases (10 females, 20 males, mean age 23.53 years $\pm 3.49 \mathrm{SD}$ ), and 30 controls ( 5 females, 25 males, mean age 23.43 years \pm 3.95 SD) was done. Patients with CAP demonstrated a significant presence of the following four stress constructs; NAR (borderlinesignificance), MCS, NCS, and T/PC (highly significant) (Tablel). PS had a non-significant presence in cases. Multiple logistic regression was applied to identify independent predictor for CAP. However for four constructs it was not possible to cal culate odd's ratio (indirect estimate of relative risk ) with 95\% confidence intervals, as no controls exhibited, PRFQ score $>2.5$. T/PC was found to be a highly significant predictor of CAP. However, wide confidence intervals have resulted, since only 1 control demonstrated PRFQ score $>2.5$ in this category (Table 1 and 2).
The age and socioeconomic status of patients' were kept in a narrow range to select patients with similar exposure to life events and daily stressors.

\section{Discussion}

The present study found the psychological factors which impact through anxiety and related processes (TP/C, NCS, MCS), to be significant. One way for these factors to influence apical periodontitis, may be via, dental anxiety. A study found personality traits, like general anxiety states, phobias, and dysfunctional moods; to be related to dental anxiety. ${ }^{14}$ Dental anxiety, is associated with avoidance behaviour, which leads to low salivary flow, dental caries, poor oral health, and poor oral health related quality of life. 8,11,25,26,27 Another study reported uncontrollable conditions to cause increased corticoster one and catecholamines' levels as well as reduced cytotoxicity of natural killer cells. ${ }^{28}$

The relative non significance of PS and NAR, in comparison to MCS, NCS, and TP/C: points towards anxiety and related processes to be responsible for this association, as opposed to depression.

Lifestyle (oral hygiene neglect, smoking, more dietary fat and sugar); Inflammation (cellular and humoral immunity alteration); Environment (modification of microbial biofilm); and Genes (Individual variation in host response) have been implicated as the factors through which stress influences periodontal disease. ${ }^{21,22}$

Research on association of stress with various systemic diseases shows its physiological mediation through either mainly HPA (hypothalamicpituitary- adrenal) axis, or through sympathetic nervous system. Stimulation of HPA axis importantly stimulates production of cortisol from adrenal cortex.

Cortisol and catecholamines have the following detrimental actions: Increased blood pressure, elevation of lipids and glucose in blood stream, increased platelet activation and aggregability, decreased saliva production, altered salivary composition, increased level and variability of 
Table 1: Comparison of the psychological stress dimensions in patients with and without CAP

$\begin{array}{lccc}\text { Psychological stress dimensions } & \begin{array}{c}\text { Frequency of cases } \\ \text { with dimension } \\ \text { score }>2.5(n=30)\end{array} & \begin{array}{c}\text { Frequency of controls } \\ \text { with dimension } \\ \text { score }>2.5(n=30)\end{array} & \text { p-value }\end{array}$

\begin{tabular}{lccccc} 
& $\mathrm{N}$ & $\%$ & $\mathrm{~N}$ & $\%$ & \\
\hline Perceived stress & 2 & 6.7 & 0 & 0 & .492 \\
\hline Negative affective regulation & 5 & 16.7 & 0 & 0 & .052 \\
\hline Maladaptive coping style & 6 & 20 & 0 & 0 & .024 \\
\hline Temperamental/personality characteristic & 14 & 46.7 & 1 & 3.3 & $<001$ \\
\hline Negative cognitive schema & 6 & 20 & 0 & 0 & .024 \\
\hline
\end{tabular}

Score $>2.5$ on the PRFQ questionnaire refers to the significant presence of that dimension in the patient.

$P$ value $\leq 0.05$ was set as level of statistical significance.

Table 2: Multiple logistic regression analysis of psychological stress dimensions having a significant association with CAP.

$\begin{array}{lccc}\text { Psychological stress dimensions } & \text { Odds ratio } & 95 \% \text { confidence interval } & \text { p-value } \\ \text { Temperamental/personality characteristic } & 25.4 & 3.05-211 & <001\end{array}$

muscle tension, decreased production of cytokines, suppressed circulating lymphocytes, decreased natural killer cells number, decalcification of bone, and delayed wound healing. 19,22,23

These psycho-physiological effects along with stress related altered cognition and behaviour may be playing a role in apical periodontitis.

The present study had limitations like usage of pilot convenient sample, cross sectional nature, and subjectivity of the questionnaire method. However with no reported study on this topic the present study investigates and brings to light a new association.

The implications of the association found in the present study are twofold: pointing association of psychological risk factors with chronic apical periodontitis, and secondly recognising the need to integrate behaviour modification into treatment protocol, to manage this stress. ${ }^{29}$

Within limitations of this pilot investigation, we conclude that patients with chronic apical periodontitis demonstrated significant presence of psychol ogical risk factors, such as, negative affective regulation (borderline), maladaptive coping style, temperamental/personality characteristic and negative cognitive schemas. Psychological dimension of temperamental/personality characteristic, which impacts through anxiety and related processes, demonstrated 25.4 times higher odds, for having CAP.

\section{References}

1. Costa THR, Figueiredo J ade, Oliveria Aefde, Maia Mdefle, Almeida Alde. Association between chronic apical periodontitis and coronary artery disease. J Endod 2014; 40:164-167.

2. Nayak M, Kumar J, L KP. A radiographic correlation between systemic disorders and pulp stones. Indian J Dent Res 2010; 21:369-373.

3. Segura-Egea J , J imenez-Pinzon A, Rios-Santos J V, VelascoOrtega E, Cisneros-Cabello R, Poyato-Ferrera M. High prevalence of apical periodontitis amongst type 2 diabetic patients. Int Endod J 2005; 38:564-569.

4. Edds AC, Walden J E, Scheetz J P, Goldsmith LJ , Drisko CL, Eleazer PD. Pilot study of correlation of pulp stones with cardiovascular disease. J Endod 2005; 31:504-506.

5. Bullon P, Newman HN, Battino M. Obesity, diabetes mellitus, atherosclerosis and chronic periodontitis: a shared pathology via oxidative stress and mitochondrial dysfunction. Periodontology 2000; 64:139-153. 
6. Vered Y, Soskolne V, Zini A, Livny A, Sgan-Cohen HD. Psychological distress and social support are determinants of changing oral health status among immigrant population from Ethiopia. Community Dent Oral Epidemiol 2011; 39:145-153.

7. Kurihara E, Neves VJ D, Kitayama VS, Endo MS, Teradai RS, Marcondes FK. Relationship between oral health and psychological factors in institutionalized and noninstitutionalized elderly individuals. Rev Gaucha Odontol, 2013; 61(2):177-186.

8. Mejia-Rubalcava C, Alanis-Tavira J, Argueta-Figueroa L, Legorreta-Reyna A. Academic stress as a risk factor for dental caries. Int Dent J 2012; 62: 127-131.

9. Pani SC, Odhaib M AL. The impact of dental treatment on the salivary cortisol levels of children with severe early childhood caries. Eur Arch Paediatr Dent 2013; 14:307-312.

10. Thomson WM, Broadbent J M, Locker D, Poulton R. Trajectories of dental anxiety in a birth cohort. Community Dent Oral Epidemiol 2009; 37:209-219.

11. Eitner S, Wichmann M, Paulsen A, Holst S. Dental anxiety - an epidemiological study on its clinical correlation and effects on oral health. J Oral Rehab 2006 33;588-593.

12. Klages U, Ulusoy O, Kianifard S, Wehrbein H. Dental trait anxiety and pain sensitivity as predictors of expected and experienced pain in stressful dental procedures. Eur J Oral Sci 2004; 112:477-483.

13. Armfield J M. Towards a better understanding of dental anxiety and fear: cognitions vs. experiences. Eur J Oral Sci 2010; 118:259-264.

14 Thomson WM, Locker D, Poulton R. Incidence of dental anxiety in young adults in relation to dental treatment experience Community Dent Oral Epidemiol 2000; 28:289294.

15. Winocur E, Uziel N, Lisha T, Goldsmith T, Eli I. Selfreported Bruxism - associations with perceived stress, motivation for control, dental anxiety and gagging. J Oral Rehab 2011; 38:3-11.

16. Hegde M N, Hegde N D, Ashok A, Shetty S. Evaluation of total antioxidant capacity of saliva and serum in cariesfree and cariesactive adults: An in-vivo study. Indian J Dent Res 2013; 24(2):164-167.

17. Salim S. Oxidative stress and psychological disorders. Curr Neuropharmacol 2014; 12(2):140-147.
18. Cohen S, Kessler RO, Gordon LU. 1995. Measuring stress: A guide for health and social scientists. New York: Oxford University Press.

19. Steptoe A. Psychophysiological basis of disease. In: Bellack AS and Hersen $M$, editors. Comprehensive clinical psychology. Elsevier Science Ltd; 1998. pgs. 39-78.

20. Sinha UK, Desai NG, Gupta DK, Tripathi CB, Sisodia A, Kumar J , Shah B, Mathur P. Development of Psychological Risk Factors Questionnaire (PRFQ). Psychological Studies 2008, 53(2):146-149.

21. Mousavijazi M, Naderan A, Ebrahimpoor M, Sadeghipoor $M$. Association between Psychological Stress and Stimulation of Inflammatory Responses in Periodontal Disease. J Dent 2013; 10(1):103-111.

22. Akcali A, Huck O, Tenenbaum H, Davideau J I, Buduneli N. Periodontal diseases and stress: a brief review.J Oral Rehab 2013; 40;60-68.

23. Brandini DA, Benson J, Nicholas MK, Murray GM, Peck CC. Chewing in temporomandibular disorder patients: an exploratory study of an association with some psychological variables. J Orofac Pain 2011; 25:56-67.

24. Hembrecht EJ , Nieuwenhuizen J, Aartman Iha, Krikken J , Veerkamp J SJ. Pain-related behaviour in children: a randomised study during two sequential dental visits. Eur Arch Paediatr Dent 2013; 14:3-8.

25. Goettems ML, Ardenghi TM, Demarco F, Romano AR, Torriani D. Children's use of dental services: Influence of maternal dental anxiety, attendance pattern, and perception of children's quality of life. Community Dent Oral Epidemiol 2012; 40:451-458.

26. Wigen $\mathrm{TI}$, Skaret E, Wang NJ . Dental avoidance behaviour in parent and child as risk indicators for caries in 5-yearold children. Int J Paed Dent 2009; 19:431-437.

27. Acharyaa S. Oral health-related quality of life and its associated factors in an Indian adult population. Oral Health Prev Dent 2008; 6:175-184.

28. Steptoe A, Appels A. Editors. 1989. Stress, personal control and health, Chichester, UK. Wiley.

29. Singh H, Meshram GK, Warhadpande M, Kapoor P. Effect of 'perceived control' in management of anxious patients undergoing endodontic therapy by use of an electronic communication system. J Conserv Dent 2012; 15:51-55. 